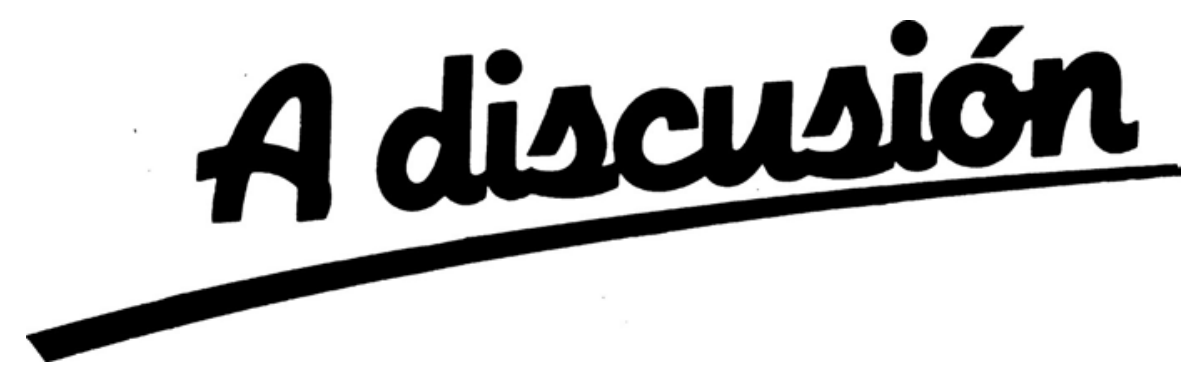

DOES FEMALE PARTICIPATION AFFECT THE SHARING RULE?*

Bernarda Zamora**

WP-AD 2007-07

Editor: Instituto Valenciano de Investigaciones Económicas, S.A.

Primera Edición Abril 2007

Depósito Legal: V-1904-2007

IVIE working papers offer in advance the results of economic research under way in order to encourage a discussion process before sending them to scientific journals for their final publication.

\footnotetext{
* The paper benefited from the comments and discussion by César Alonso, Dolores Collado and Aurora GarcíaGallego. Financial support by the Spanish Ministry of Education (project SEJ2005-02829/ECON) is gratefully acknowledged. I remain responsible for all errors and omissions.

** Departament d'Economia. Universitat Jaume I, Campus Riu Sec, E-12071 Castellón (Spain). Tel: +34964387166. Fax: +34964728591. E-mail: zamoram@eco.uji.es
} 
DOES FEMALE PARTICIPATION AFFECT THE SHARING RULE?

\title{
Bernarda Zamora
}

\begin{abstract}
Using Spanish data I test whether there is a different pattern of intra-household distribution between two types of families: on the one hand, families with both spouses in full time employment and, on the other hand, families with the husband in full time employment and the wife being outside the labor market. Significant differences are found in such a pattern and some of its features are identified and estimated.
\end{abstract}

Keywords: collective model, sharing rule, female participation, Engel curve

JEL codes: D11, J22 


\section{Introduction}

The traditional sociological view is that the Spanish family is ruled by a paterfamilias who acts as a supreme decision maker and administrator of the pooled resources of the family members (Moreno, 2003). This view is close to the traditional unitary economic model of the household as a single decision maker. Nevertheless, empirical evidence rejects the restrictions imposed by the unitary model. In particular, the rejection of the Income Pooling Hypothesis is common, according to which only total family income, and not its distribution across members, matters for labor supply and consumption decisions (see Lundberg and Pollak (1996) for a survey). Furthermore, as remarked in Blundell et al. (2001), the unitary model implies "...that if an individual is at a corner solution, it is the reservation wage of that individual rather than the market wage that affects the labor supply of the partner. As in the case of the income pooling assumption, this is far from innocuous, implying as it does that the value of paid work as an 'outside option' for a nonparticipant does not influence the allocation of consumption and leisure within the household" (p.2).

I provide herein additional empirical evidence against the traditional view of the Spanish family. To tackle this problem I compare the distribution of resources between the spouses in two types of families. On the one hand, traditional families considered as those families in which the wife does not participate in the labor market and, on the other hand, modern families considered as those in which the wife participates.

It is well-known that the identification of the intra-household distribution can only be done by modelling the household outcomes as the result of many people's (at least two adults) decisions. Amongst the many models suggested, empirical evidence supports to the collective model for several countries. This model posits that however decisions are made, the outcomes are Pareto efficient (see Chiappori $(1988,1992)$ and Browning and Chiappori (1998) for the basic theory). The pattern of intra-household distribution is known as "the sharing rule" in this family of collective models. 
The starting point of the present work is the basic collective model of Chiappori $(1988,1992)$ in which the goods of interest are a composite commodity and the spouses labor supplies. For my purposes, I take the spouses' labor supplies as given and thus I condition the free choice of commodities by some taken values of both labor supplies and participation. In this way my model approaches to the conditional model of Browning and Meghir (1991), but I extend their (unitary) conditional model in the collective way so that I allow for wage effects on commodity demands by virtue of the collective bargaining effects. As already remarked by Browning and Meghir (1991), the conditional approach I employ has the advantage that "our conclusions do not depend on us having the correct model of the determination of labor force participation and hours of work". This advantage allow us the use of the basic collective model plus an assumption of existence of two exclusive commodities to identify the sharing rule in non-participating households. The same identification method has been used by of Browning et al. (1994) but only with respect to households in which both spouses work full time.

Extended collective models which explicitly model non-participation and identify the sharing rule from this extended theoretical setting can be seen in Blundell et al. (2001) and Donni $(2001,2003)$. These models are extended in the sense that they can identify the sharing rule in non-participation sets without relying on the assumption of existence of two exclusive commodities. However, these models do not provide enough evidence about the pattern of change of the sharing rule across different participation regimes. The theoretical model of Blundell et al. (2001) imposes a priori the existence of two different patterns of the sharing rule: one in the participation regime, and the other in the non-participation regime. In the same line and from a theoretical perspective, Donni (2001) presents the identification of two sharing rules in either regime. However, Donni (2003) presents an estimation of a unique sharing rule for both regimes consistent with his theoretical model.

In the conditional model presented here, the answer to the question of whether there is a unique sharing rule across regimes or a pair of sharing rules in each regime is a matter 
of empirical evidence. Indeed, instead of imposing a particular relationship between the pair of sharing rules, we can test whether the particular relationship between the pair of sharing rules imposed by the model of Blundell et al. (2001) holds. Therefore, one of the contributions of this paper is the finding of empirical restrictions across regimes (subject to a particular functional form) to test the null hypothesis of a unique sharing rule.

The conditional methodology used comes out as the simplest way (in the sense that I do not extend the collective basic model) that has been used under the collective framework to recover the sharing rule under non-participation in the labor market. This simplicity arises at the cost of assuming the observability of two exclusive commodities such as men's and women's clothing. The counterpart of this cost is that it allows to test the existence of a unique sharing rule across regimes and to identify, in the case of a rejection of the test, the two different sharing patterns: one for 'traditional' households in which the wife does not participate and the other one for 'modern' households in which the wife participates.

Under the theoretical model assumptions we find how several variables, such as the household income and the labor incomes of the spouses, affect each partner share of total expenditures and whether these effects are different depending upon the wife's participation in the labor market. The estimates provide evidence against the income pooling hypothesis and also against the hypothesis of a unique sharing rule. However, there is no evidence against some of the collective model properties. The test of the Blundell et al. (2001) implication of a positive proportionality between the parameters of the two sharing rules gives a p-value of 4.5 percent. Therefore, we cannot state that any strong evidence exist to support the proportionality, although we can see that it has a positive sign.

Previous estimates of the effect of wealth and wages on the sharing rule have found different results for different countries. In contrast with the results found here concerning the effect of non-labor income, Blundell et al. (2001), Chiappori et al. (2002) and Donni (2001) find a much larger positive effect of non-labor income on the wife's share. In line with the results presented here, Blundell et al. (2001) and Browning et al. (1994) point out 
a positive effect of the wife's wage on her share. With respect to the effect of the husbands wage, results found in this paper are in line with those in Donni (2001), in the sense that an increase in the husband's wage is shared between the spouses. In short, I find that, in Spanish households, the 'welfare' effect, consisting of a transfer to the partner, dominates the 'distribution' effect, consisting of an spouse keeping all of her/his wage increase plus and extra due to the increase in her/his bargaining power. The net effect results in the sharing between the spouses of any accrual in wages. In the case of households in which the wife is outside the labor market, the transfer to the wife caused by an increase in the husband's wage is higher than in the case of households with both spouses working full time.

The paper is structured as follows. Section 2 presents the theoretical framework. Section 3 explains the parametric specification used for estimating and testing. Section 4 presents the data, estimation method and empirical results . Finally, Section 5 sets out some concluding remarks.

\section{The Theoretical Framework}

\section{A. The Model}

Following Browning et al. (1994), the model presented is defined under the following assumptions:

(i) Pareto efficient outcomes that are the result of the decision process between two agents, the wife and the husband $(i=f, m)$.

(ii) Observability of the amount of total household private expenditures among which we consider a private Hicksian composite consumption good $C$, and two exclusive consumption goods (or one assignable good): women's clothing and men's clothing, $q^{f}, q^{m}$. The distribution of $C$ between the spouses such that $C=C^{m}+C^{f}$ is not observed.

(iii) Egoistic preferences over private goods or egoistic and weakly separable preferences over private and public goods. 
In our conditional framework, among the variables that condition the choice of private consumption goods there are labor supplies, $h^{f}, h^{m}$, participation dummies $d^{f}, d^{m}$, and a vector $z$ of demographics and goods such as durables. With $M$ we denote the total expenditure in private goods, while $Q$ denotes the total expenditure in public goods. The household sources of income are labor incomes expressed as products of wages by working hours, $w^{f} h^{f}, w^{m} h^{m}$, and non-labor income, $y$.

Labor supply is a special case of a conditioning good since the corner solution in the labor supply of the spouses could lead to a switching in the demand system between the unrationed and rationed systems. Browning and Meghir (1991) allow for the switching of the demand system in the conditional framework by incorporating fixed costs of participation in the conditional cost function. In their model, the fixed costs shift only the intercept of the demand system. However, they also note that these sorts of cost may alter the level of total expenditure as well as the structure of demand.

Under these assumptions, household behavior must be the solution of the following program:

$$
\begin{gathered}
\max _{q^{f}, q^{m}, C^{f}, C^{m}} \quad \mu(\delta) U^{f}\left(q^{f}, C^{f} ; h^{f}, h^{m}, d^{f}, d^{m}, z\right)+(1-\mu(\delta)) U^{m}\left(q^{m}, C^{m} ; h^{f}, h^{m}, d^{f}, d^{m}, z\right) \\
\text { subject to: } \quad q^{f}+q^{m}+C=M
\end{gathered}
$$

where $M=w^{f} h^{f}+w^{m} h^{m}+y-Q$.

The existence of a differentiable function $\mu(\delta)$ guarantees that a unique, well-defined outcome exists. Any point of the Pareto frontier can be obtained for some chosen $\mu$ such that a higher value of $\mu$ gives more weight to the wife's preferences compared to the husband or more 'power' to the wife. The distribution of 'power' between the husband and the wife depends on the vector of variables $\delta$ which includes commodity prices (set equal to one) and income, measured by $M$. Vector $\delta$ may include all exogenous variables of the demand system and any exogenous variable affecting the bargaining position between the spouses (extra-environmental parameters in the terminology of McElroy (1990) or distribution 
factors in the terminology of Browning et al. (1994)). In particular, wages, including the potential wages of nonparticipants, are normally considered to affect $\mu$ and, in our case, wages are distribution factors since their effect on the demand system is transmitted uniquely through the function $\mu$.

The values taken for the spouses labor supplies are such that $h^{m}=d^{m}=1$ for men, that is, the husband always works full time, and $h^{f}=1$ if $d^{f}=1$ or $h^{f}=0$ if $d^{f}=0$ for women, that is, the wife, when she works, always works full time. Hence, we define households in either the participation regime $\left(d^{f}=1\right)$ or in the non-participation regime $\left(d^{f}=0\right)$.

\section{B. The Sharing Rule Interpretation}

Chiappori (1992) shows (by virtue of the Second Welfare Theorem) that the solution of program $\bar{P}$ is the solution of the two following individual programs for $i=m, f$ :

$$
\begin{gathered}
\max _{q^{i}, C^{i}} \quad U^{i}\left(q^{i}, C^{i} ; d^{f}, z\right) \\
\text { subject to: } \quad q^{i}+C^{i}=\varphi^{i}(\delta) M
\end{gathered}
$$

where the function $\varphi(\delta)=\varphi^{f}(\delta)$ denotes the proportion of private expenditures received by the wife, and $1-\varphi(\delta)=\varphi^{m}(\delta)$ is the proportion of private expenditures the husband receives. The function $\varphi(\delta)$ represents the "sharing rule". Given that the sharing rule may depend on any exogenous variable of the model, the participation dummy can be a component of $\delta$. The relevant question now is the following: does the conditioning variable female participation affect the sharing rule to the point of switching its parameters?

Extended collective models discussed in the introduction impose the existence of two sharing rules in each regime (Blundell et al. (2001) and Donni (2001)) or the existence of a unique sharing rule for both regimes (Donni (2003)). One of the main objectives of the present analysis is to test whether there are significant differences in the sharing 
rule parameters across regimes. For this reason, I do not impose in the model that the sharing rule must depend upon female participation and that, therefore, such a relation of dependence is the cause for the switching of the sharing rule across regimes.

I consider the sharing rule to depend only on household wealth, measured by the amount of household private expenditures, and on wages. Therefore, the sharing rule can be written as the function $\varphi\left(M, w^{m}, w^{f}\right)$. For simplicity, other potential distribution factors, such as differences in ages or in levels of education of the spouses, are not included.

\section{Parametric Identification}

I assume a semi-logarithmic functional form for the Engel curves of clothing consumption of each spouse. The explanatory variables of the Engel curves are the unobserved individual private expenditures, $x^{i}$, and the vector $z$ of demographic variables and durables. Omitting the vector $z$, the individual Engel curves are represented by the following equations:

$$
\begin{gathered}
q^{f}=a^{f}\left(d^{f}\right)+b^{f}\left(d^{f}\right) \log x^{f}, \quad \text { with } \quad x^{f}=M \varphi\left(M, w^{f}, w^{m}\right) \\
q^{m}=a^{m}\left(d^{f}\right)+b^{m}\left(d^{f}\right) \log x^{m}, \text { with } x^{m}=M\left(1-\varphi\left(M, w^{f}, w^{m}\right)\right)
\end{gathered}
$$

This modelization allows for the most general effect of the participation dummy on the parameters of the Engel curves, so that female participation can shift all the parameters. Therefore, the consumption of the two exclusive commodities is represented by the following structural system formed by four Engel curves:

$$
\begin{gathered}
q^{f}=a_{0}^{f}+b_{0}^{f} \log x^{f} \quad \text { if } \quad d^{f}=0 \\
q^{f}=a_{1}^{f}+b_{1}^{f} \log x^{f} \quad \text { if } \quad d^{f}=1 \\
q^{f}=a_{0}^{m}+b_{0}^{m} \log x^{m} \quad \text { if } \quad d^{f}=0 \\
q^{f}=a_{1}^{m}+b_{1}^{m} \log x^{m} \quad \text { if } \quad d^{f}=1
\end{gathered}
$$


Inspired by Browning et al. (1994), the following logistic functional form represents the sharing rule:

$$
\varphi\left(M, w^{f}, w^{m}\right)=\frac{\exp \left(\psi\left(M, w^{f}, w^{m}\right)\right)}{1+\exp \left(\psi\left(M, w^{f}, w^{m}\right)\right)}
$$

where

$$
\psi\left(M, w^{f}, w^{m}\right)=2\left(\alpha+\theta \ln M+\gamma_{f} \ln w^{f}+\gamma_{m} \ln w^{m}\right)
$$

The sharing rule is bound between zero and one and takes the equal sharing value, 0.5 , for $\psi=0$. The constant term $\alpha$ centers the function so that the lower the value of $\alpha$ the lower the wife's share is. Parameters $\theta, \gamma_{f}$ and $\gamma_{m}$ define the elasticities of the sharing rule with respect to non-labor income and wages as the expressions given below.

The accrual of the spouses' shares caused by a change in non-labor income (increase in $M$ with no change in labor incomes) and by a change in labor incomes is measured by the following derivatives:

$$
\begin{gathered}
\frac{\partial x^{f}}{\partial M}=\varphi(1-\varphi) 2 \theta+\varphi \\
\frac{\partial x^{m}}{\partial M}=-\varphi(1-\varphi) 2 \theta+(1-\varphi) \\
\frac{\partial x^{f}}{\partial w^{i}}=\varphi(1-\varphi) 2 \gamma_{i}+\varphi \\
\frac{\partial x^{m}}{\partial w^{i}}=-\varphi(1-\varphi) 2 \gamma_{i}+(1-\varphi)
\end{gathered}
$$

With respect to the effect of the wife's potential wage, which does not affect $M$, the last summand of the right hand side of expressions (11) and (12) is zero.

The expressions of the income elasticity and wages elasticities of the sharing rule can be seen in Browning et al. (1994). According to the value taken by the income elasticity of the wife's share at the equal sharing point, $\theta+1$, the wife's share is a luxury and the husband's share a necessity if $\theta$ is positive. Conversely, the wife's share is a necessity and the man's share a luxury is $\theta$ is negative.

Equations (3) to (6) could be estimated by nonlinear ordinary least squares and the identification of the parameters of the sharing rule would be partly due to non-linearity 
of the specification. However, as Chiappori $(1988,1992)$ shows, non-linearity of the Engel curves is not a necessary condition to identify the parameters of the sharing rule. In fact, Chiappori shows that under the basic assumptions, the parameters of the sharing rule are identified up to a constant. Accordingly, in the following linearized model, I show that all the parameters of the sharing rule, with the exception of $\alpha$, are identified.

The sharing rule is linearized by taking a Taylor expansion around the equal sharing point and a logarithmic approximation according to which $\ln (1+\epsilon) \simeq \epsilon$, for $\epsilon$ close to zero (this linearization method is taken from the Appendix A in Browning et al. (1994)).

$$
\begin{gathered}
\ln \varphi(\psi)=\ln \frac{1}{2}+\ln \left(1+\frac{\psi}{2}\right) \simeq \ln \frac{1}{2}+\frac{\psi}{2} \\
\ln (1-\varphi(\psi))=\ln \frac{1}{2}+\ln \left(1-\frac{\psi}{2}\right) \simeq \ln \frac{1}{2}-\frac{\psi}{2}
\end{gathered}
$$

By substituting expressions (13) and (14) into the Engel curves (3) to (6), we obtain a linear in variables structural form for the Engel curves, whose reduced forms can be estimated by linear methods. If we add the demographic variables again in the vector $z$, these reduced forms are:

$$
\begin{gathered}
q^{f}=A_{0}^{f}+B_{0}^{f} \log M+C_{0}^{f} \log w^{f}+D_{0}^{f} \log w^{m}+E_{0}^{f} z \quad \text { if } \quad d^{f}=0 \\
q^{f}=A_{1}^{f}+B_{1}^{f} \log M+C_{1}^{f} \log w^{f}+D_{1}^{f} \log w^{m}+E_{1}^{f} z \quad \text { if } \quad d^{f}=1 \\
q^{m}=A_{0}^{m}+B_{0}^{m} \log M+C_{0}^{m} \log w^{f}+D_{0}^{m} \log w^{m}+E_{0}^{m} z \quad \text { if } \quad d^{f}=0 \\
q^{m}=A_{1}^{m}+B_{1}^{m} \log M+C_{1}^{m} \log w^{f}+D_{1}^{m} \log w^{m}+E_{1}^{m} z \quad \text { if } \quad d^{f}=1
\end{gathered}
$$

Assuming a priori that female participation does not affect the sharing rule, each of the sixteen reduced form parameters, $A_{k}^{i}, B_{k}^{i}, C_{k}^{i}, D_{k}^{i}$ for $i=m, f$ and $k=0$ or $k=1$, can be expressed as a function of twelve structural parameters $a_{k}^{i}, b_{k}^{i}, \alpha, \theta, \gamma_{f}, \gamma_{m}$ for $i=m, f$ and $k=0$ or $k=1$ (see the system of identifying equations in the Appendix A). In the identification system we see that the intercepts $a_{k}^{i}$ of the Engel curves and the intercept $\alpha$ 
of the sharing rule are not identified. The rest of the parameters are not uniquely identified. The identification system consists then of twelve equations in seven unknowns. Therefore, the identification system implies five overidentifying restrictions. But then, if we allow for the switching of the sharing rule across regimes, we have an initial system of sixteen equations in sixteen unknowns, which shows the same underidentification for $a_{k}^{i}$ and $\alpha_{k}$ and two overidentifying restrictions for the remaining parameters (twelve equations in ten unknowns).

The identification system corresponding to a unique sharing rule imposes the following restrictions on the reduced form parameters:

$$
\begin{gathered}
\frac{C_{0}^{f}}{D_{0}^{f}}=\frac{C_{0}^{m}}{D_{0}^{m}} \\
\frac{C_{1}^{f}}{D_{1}^{f}}=\frac{C_{1}^{m}}{D_{1}^{m}} \\
\frac{C_{0}^{i}}{D_{0}^{i}}=\frac{C_{1}^{i}}{D_{1}^{i}} \quad i=m, f \\
\frac{B_{0}^{i}}{C_{0}^{i}}=\frac{B_{1}^{i}}{C_{1}^{i}} \quad i=m, f \\
\frac{B_{0}^{i}}{D_{0}^{i}}=\frac{B_{1}^{i}}{D_{1}^{i}} \quad i=m, f
\end{gathered}
$$

In the terminology of collective models (Browning and Chiappori (1998)), restrictions $(D F P 0)$ and $(D F P 1)$ result from the Distribution Factor Proportionality property $(D F P)$. This property holds even in the case in which the sharing rule switches across regimes. A test of restrictions $(D F P 0)$ and $(D F P 1)$ allows us to test necessary conditions of the Pareto efficiency assumption. Since our distribution factors are the spouses wages, the unitary model property income pooling is a particular case of the DFP property when the ratio $C_{k}^{i} / D_{k}^{i}=1$ for $i=m, f$ and $k=0$ or $k=1$. Income pooling is a necessary condition in any classical single decision maker model.

Restrictions $\left(R 1^{i}\right)$ to $\left(R 3^{i}\right)$ hold when the sharing rule does not depend on female participation. These restrictions are necessary conditions for a unique sharing rule across 
regimes to exist. A test of a sufficient condition for an equal sharing rule across regimes is provided by the test of the five overidentifying restrictions of the identification system.

\section{Evidence from Spanish Data}

\subsection{Description of the Data}

The data used in this analysis are data on household expenditures and have been obtained from the Spanish expenditures survey "Encuesta de Presupuestos Familiares 1990-91" $(\mathrm{EPF}-90)^{1}$. The sample selected consists of couples whose members are less than sixty-six and with the husband working full time. I assume the couple are the two adult decisionmakers. Among these households, there are 1,509 households in which the wife works full time and 3,369 in which the wife does not participate in the labor market. (See detailed sample selection in Table VI).

I allow for the existence of children under the age of seventeen. Although the inclusion of couples with children is controversial since children can be considered as public goods and are the main source of preference interdependence between the spouses, I decided to include couples with children because choosing only childless couples restricts the size of our sample too much. Part of the public element problem is mitigated by excluding reported expenditures on children from private expenditures.

To estimate Engel curves for men's and women's clothing I use data from EPF-90 on clothing expenditures by gender, as well as on household private expenditures, on spouses labor incomes and on household characteristics. I consider the following expenditures to be private expenditures: food, transport and communications, clothing, personal care, home entertainment, outside home entertainment, alcohol and tobacco, and a group of other miscellaneous expenditures. Then, to measure total private expenditures I exclude those

\footnotetext{
1 Data and documentation are available at the web page of the Department of Economics of the University Carlos III of Madrid: http://www.eco.uc3m.es/investigacion/index.html $\sharp$ toc4.
} 
that are considered public goods (children expenditures as well as those for energy, water, cleaning and housing) from the total current expenditures.

The EPF-90 does not include data on working hours. Agents report whether or not they work full time and their labor incomes. Assuming, as the theoretical model does, that everybody working full time works the same amount of annual hours, allows us to use the spouses labor incomes as explanatory variables of the Engel curves. However, the study of the distribution of weekly working hours with data of the Spanish Labor Force Survey (Encuesta de Población Activa) for those who report working full time indicates a wide distribution of working hours. Therefore, to normalize working hours, we use hourly wages as labor incomes measure. The hourly wage has been imputed as the ratio of labor income to the imputed annual working hours. The imputation of working hours has been done from the Encuesta de Población Activa data on working hours and on individual characteristics which can be matched to the characteristics of individuals in the EPF-90 data (more details on the methodology of such imputation can be seen in Zamora (2004)).

Sample statistics of men's and women's clothing as well as on selected explanatory variables are shown in Table I.

\subsection{Econometric Issues}

In the estimation of the system formed by the two Engel curves of men's and women's clothing I allow for endogeneity of female participation although it is not a choice in the theoretical model (see Browning and Meghir (1991)). Then, considering that female participation switches all the parameters of the Engel curves implies that we have to model endogenous switching. Moreover, as we need to test the cross-regimes restrictions $\left(R 1^{i}\right)$, $\left(R 2^{i}\right)$ and $\left(R 3^{i}\right)$, we have to jointly estimate the participation system formed by equations (16) and (18) and the non-participation system formed by (15) and (17). Therefore, we 
can write a stochastic version of these equations for $i=m, f$ as (see Maddala, (1983)):

$$
q^{i}=d^{f} q_{1}^{i}+\left(1-d^{f}\right) q_{0}^{i}=X \beta_{0}^{i}+\widehat{\Phi} X\left(\beta_{1}^{i}-\beta_{0}^{i}\right)+\left(\sigma_{0 D}^{i}-\sigma_{1 D}^{i}\right) \widehat{\phi}+e
$$

where $X$ is the matrix with all the explanatory variables, $\beta_{1}^{i}$ and $\beta_{0}^{i}$ are vectors of parameters corresponding to the participation and non-participation regimes respectively, $\widehat{\Phi}$ and $\widehat{\phi}$ are respectively the point estimates of the normal cumulative and probability distribution functions of the participation equation that has been estimated in a first stage, $\sigma_{k D}^{i}$ is the covariance between the random disturbances of the participation equation and the Engel curve in the $k$ regime for $k=0$ or $k=1$, and $e$ is a mean zero error that is not related to participation. The random disturbances of clothing consumptions and of participation are assumed to follow a trivariate normal. The self-selection parameter $\left(\sigma_{0 D}^{i}-\sigma_{1 D}^{i}\right)$ indicates whether there are unobserved gains or losses in clothing consumption of the spouse $i$ derived from female participation.

Measurement problems of consumption from expenditure data (bulk purchases and infrequency of purchase) are taken into account. The data available for food are already corrected by bulk purchases according to the methodology proposed by Peña and RuizCastillo (1992). Clothing and the components of private expenditures, with the exception of transport and communication and alcohol and tobacco, have been corrected by infrequency according to the methodology of Meghir and Robin (1992).

Lumpiness and infrequency may induce an endogeneity of the explanatory variable ‘total private expenditures'. Therefore, we have two endogenous explanatory variables in each equation of the system (19): the logarithm of per capita private expenditures, and the product of this variable by the predicted probability of female participation, $\widehat{\Phi}$. We use four instruments based on income variables to have some overidentification: As a first instrument, we use the logarithm of a proxy variable for income that includes all expenditures on durables and non-durables ${ }^{2}$. The second instrument results as the product

\footnotetext{
2 This variable has been previously used in Deaton et al. (1989) to instrument current expenditure.
} 
of the first instrument by the reported total household income. Finally, the two remaining instruments are the product of the two previous instruments by $\widehat{\Phi}$. If we only use functions of reported income as instruments, we find we have a problem of weak instruments because of the weak relationship between reported income and household private expenditures.

Wages are imputed for husband and for working wives according to the above-described procedure. When the wife does not participate, her potential wage is predicted from a wage equation that corrects self-selection from a participation equation (see estimates in Table VIII). I consider wages as exogenous variables by considering that agents cannot affect wages once they have decided their labor supply.

The system (19) formed by the reduced form equations corresponding to men's and women's clothing is estimated using the generalized method of moments (GMM). The income pooling, the distribution factor proportionality and the equal sharing rule restrictions are tested upon the basis of these estimates. The Hansen test is applied to the GMM estimates of each equation separately to test the validity of the instruments.

A minimum distance estimator is used to solve the identification system, that is, estimates for the individual marginal propensities to consume and the sharing rule parameters are recovered. Demographic and household characteristics variables are included in the structural form .

\subsection{Results}

The reduced form estimates are presented in Table II. The relevant estimates for the identification system are the coefficients of 'private expenditures' and of 'wages'. With respect to these parameters we observe the following features.

Household income elasticities $\left(\frac{\partial \log q^{i}}{\partial \log M}=B^{i} / q^{i}\right)$ indicate that men's clothing is a luxury in both regimes, with an income elasticity of approximately 1.3. However, women's clothing is a necessity in the non-participation regime (elasticity of 0.8) and a luxury in 
the participation regime (elasticity of 1.9). The men's wage has a negative effect on men's clothing in the non-participation regime. One should bear in mind that this effect is controlled for a measure of household wealth and for the husband level of education whose effects are large and positive. No significant effect of female wages is observed in either regime.

With respect to the effect of household characteristics and demographic variables on men's clothing, it is remarkable that men's clothing consumption increases substantially with the number of children. This increase does not seem to be due to the reporting of children's clothing into the husband's clothing, since such an increase happens only for men's clothing and just in the non-participation regime. This result for men's clothing contrasts with that obtained by Deaton et al. (1989) for adult clothing and for a much larger sample of Spanish data. They find that all the child groups have significant negative coefficients in the adult clothing equation. In my case, I obtain these negative effects of children on clothing for the case of women's clothing in the non-participation regime, although these effects are not precisely estimated. The results in Deaton et al. (1989) detect non-separabilities among adult clothing and the presence of children. The nonseparability implies that the effect of the child on adult clothing consumption contains substitution effects. The fact that adult clothing is not demographically separable from children is not consistent with the model assumption of weak-separability among private and public goods. Later I discuss how to consider this inconsistency.

The patterns of complementarities or substitutabilities between durables and men's clothing change across regimes. While the non-participating household sacrifices men's clothing in order to buy more durables other than the car, the participating household sacrifices men's clothing in order to buy the car. However, the remaining durables are complements of men's clothing.

In the case of women's clothing, apart from regional fixed effects, the unique significant effects at an individual level are those of private expenditures and home ownership. Home 
ownership favors the consumption of clothing of the non-participating wife but apparently the participating wife sacrifices her clothing expenditures to pay the mortgage.

There is not evidence of selectivity, that is, unobserved gains in clothing derived from participation are not taken into account when the household decides on the wife's participation.

Table III presents the test of the reduced form model restrictions. By testing such restrictions we conclude that we reject only the unitary model property of income pooling. This rejection is due to the result of the bargaining decision process in households in which the wife does not participate. Distribution Factor Proportionality is not rejected. Therefore, there is no evidence against the collective theoretical setting. Equal sharing rule restrictions $\left(R 1^{i}\right),\left(R 2^{i}\right)$ and $\left(R 3^{i}\right)$ are not rejected but this is not sufficient to assert that the sharing rule does not depend upon female participation.

Household composition effects that result from the inclusion of children effects cause problems of identification of the structural model. The identification system includes restrictions of equality between the parameters of the reduced form and the structural form corresponding to demographic and household characteristics variables. It happens that the restrictions concerning this equality between the parameters of household composition in the reduced and structural form systems are rejected. As a consequence, the two overidentifying restrictions of the identification system corresponding to the general case of two sharing rules are rejected (see estimates of the structural form in Table VII). Therefore, the estimated structural model which includes children's effects is not consistent with the theoretical model. Nevertheless, when we eliminate household composition effects from the structural Engel curves (3) to (6), the estimates turn out to be consistent with the theoretical model so that we do not reject the two overidentifying restrictions of the model with two sharing rules.

The structural parameters estimates of the model without household composition 
effects are shown in Table IV and Table V. Table IV presents the sharing rule parameters estimates and Table V presents the parameters estimates for the structural Engel curves (3) to (6) (regional effects are included in the estimation but omitted in the presentation of Table V).

We reject the five overidentifying restrictions of the model with a unique sharing rule but we do not reject the two overidentifying restrictions implied by the model with two sharing rules. Thus, we find evidence against a unique sharing rule ${ }^{3}$ but not against the existence of two sharing rules. Furthermore, as the model in Blundell et al. (2001) postulates, when we allow the switching of the sharing rule across regimes we find a positive relationship between the parameters of the sharing rule in the non-participation regime and those of the sharing rule in the participation regime. However, we reject the Wald test upon the null hypothesis of proportionality or equality among the three ratios formed by each of the three pairs of parameters of the sharing rule in either regime, $\left(\frac{\theta_{0}}{\theta_{1}}=\frac{\gamma_{m 0}}{\gamma_{m 1}}=\frac{\gamma_{f 0}}{\gamma_{f 1}}\right)$. This Wald statistic takes a value of 6.209 which for a Chi-square of two degrees of freedom gives a p-value of 4.5 percent.

Estimates of the sharing rule parameters indicate that the wife's share is a necessity with an income elasticity close to zero in both regimes. This implies that when the household non-labor income increases a thousand pesetas, this causes a very small accrual of the wife's share (in particular, 69 Spanish pesetas in the non-participation regime and no perceptible increase in the participation regime). An increase in the husband's labor income is shared between the spouses in approximately the same amount, although the 'welfare' effect or transfer to the wife is higher in the non-participation regime. There is no perceptible effect of an increase in the labor market opportunities of the non-working

\footnotetext{
3 Evidence against a unique sharing rule is found in both cases, including or not household composition effects. However, when we eliminate household composition effects, there is a problem of convergence of the structural model with a unique sharing rule (in particular for the parameter $b_{1}^{f}$ of the Engel curve in expression(4)).
} 
wife in her share. On the contrary, the increase in the market wage of the wife increases both spouses shares in the same amount.

Estimates of the structural Engel curves (3) to (6) show that individual marginal propensities to consumption are different to the household marginal propensities to consumption estimated in the reduced form. According to the estimates of the individual marginal propensities to consumption, men's clothing is a necessity (income elasticity equal to 0.68 ) and women's clothing a luxury (income elasticity equal to 3.53 ) in the non-participation regime. Income-elasticities in the participation regime are not precisely estimated.

\section{Concluding Remarks}

The literature on collective models has dealt with the identification of the intra-household process under non-participation of one of the spouses (Blundell et al. (2001) and Donni $(2001,2003))$. Notwithstanding, the focus of this literature is not on the differences in the intra-household distribution between participating and non-participating households. In this paper, I give an empirical answer to whether these differences exist and how they operate. My empirical answer is based on the identification of the intra-household distribution from interior solutions of the household allocation model of consumption. For this reason, the identification under non-participation obliges us to make an additional assumption which consists of the observability of both spouses' clothing as goods that are consumed exclusively by each spouse. Such an assumption is considered more restrictive than those assumed in the extended collective models cited above which achieve identification by modeling the corner solution in the leisure choice of one of the spouses. Nevertheless, the restrictiveness of the clothing exclusivity assumption is mitigated by the characteristics of the data available since there is an exhaustive reporting of the type of clothing by gender. In addition to reporting expenditures on adult men's and women's 
clothing shoes, the respondent to the survey reports expenditures on baby's clothing and other types of unclassified clothing.

The allowance of couples with children in our sample appears to be problematic. This problem arises through the effects of household composition in our structural model, in such a way that the inclusion of household composition in the spouses Engel curves is not consistent with the theoretical model. However, the structural estimates obtained after the elimination of children's effects appear to be robust to the inclusion of such effects, although the allowance of children's effects causes imprecision in the estimation of structural parameters.

With respect to the consideration of families in which the wife does not participate in the labor market as traditional families versus modern families in which the wife participates, we find the counterintuitive result. It happens that there is more pooling of resources in modern than in traditional families, in contrast to which sociology says about traditional families. In this sense, we find evidence of stronger bargaining between the spouses in traditional families than in moderns families because the rejection of the income pooling hypothesis is due to the behavior inside of the traditional families. Moreover, the sharing of any accrual in the spouses labor incomes is more unevenly distributed between the spouses in traditional families than in modern families. 


\section{References}

Blundell, R., P.A. Chiappori, T. Magnac and C. Meghir (2001), "Collective Labor Supply: Heterogeneity and Nonparticipation". WP01/19, The Institute for Fiscal Studies

Browning, M., F. Bourguignon, P.A. Chiappori and V. Lechene (1994), "Income and Outcomes: A Structural Model of Intrahousehold Allocation". Journal of Political Economy, 102(6), 1067-1096

Browning, M. and P.A. Chiappori (1998), "Efficient Intra-Household Allocations: A General Characterization and Empirical Test". Econometrica, 66(6), 1241-1278

Browning, M. and C. Meghir (1991), "The Effects of Male and Female Labor Supply on Commodity Demands". Econometrica, 59(4), 925-951

Chiappori, P.A. (1988), "Rational Household Labor Supply". Econometrica, 56(1), $63-90$

Chiappori, P.A. (1992), "Collective Labor Supply and Welfare". Journal of Political Economy, 100(3), 437-467

Chiappori, P.A., B. Fortin and G. Lacroix (2002), "Marriage Market, Divorce Legislation, and Household Labor Supply". Journal of Political Economy, 110(1), 37-72

Deaton, A., J. Ruiz-Castillo and D. Thomas (1989), "The Influence of Household Composition on Household Expenditure: Theory and Spanish Evidence". The Journal Of Political economy, 97(1), 179-200

Donni, O. (2001), "Collective Female Labor Supply: Theory and Application". Working Paper n. 141, CREFÉ et Université du Quebec à Montréal

Donni, O. (2003), "Collective Household Labor Supply: Nonparticipation and Income Taxation". Journal of Public Economics, 87, 1179-1198 
Fortin, B. and G. Lacroix (1997), "A Test of the Unitary and Collective Models of Household Labour Supply". The Economic Journal, 107(443), 933-955

Lundberg, S. and R. Pollak (1996), "Bargaining and Distribution in Marriage". Journal of Economic Perspectives, 10, 139-158

Maddala, G. S. (1983), Limited Dependent and Qualitative Variables in Econometrics, New York: Cambridge University Press

McElroy, M.B. (1990), "The Empirical Content of Nash-Bargained Household Behavior". The Journal of Human Resources, 25(4), 561-583

Meghir, C. and J.M. Robin (1992), "Frecuency of Purchase and the Estimation of Demand Systems". Journal of Econometrics, 53, 53-85

Moreno, L. (2003), "Bienestar Mediterráneo y Supermujeres". Documento de Trabajo 03-09, Unidad de Políticas Comparadas (CSIC)

Peña, D. and J. Ruiz-Castillo (1998), "Estimating Food and Drinks Household Expenditures in the Presence of Bulk Purchases". Journal of Business and Economic Statistics, 16(3), 292-303

Zamora, B. (2004), "The Causal Effect of Female Labour Participation on Household Consumption. Evidence from Spanish Data". Mimeo 


\section{Appendix A}

\section{Identification System}

The identification system assuming there is a unique sharing rule consists of the following sixteen equations ${ }^{4}$ for $k=0$ and $k=1$ :

$$
\begin{gathered}
A_{k}^{m}=a_{k}^{m}+b_{k}^{m}\left(\ln \frac{1}{2}-\alpha\right) \\
B_{k}^{m}=b_{k}^{m}(1-\theta) \\
C_{k}^{m}=-b_{k}^{m} \gamma_{m} \\
D_{k}^{m}=-b_{k}^{m} \gamma_{f} \\
A_{k}^{f}=a_{k}^{f}+b_{k}^{f}\left(\ln \frac{1}{2}+\alpha\right) \\
B_{k}^{f}=b_{k}^{f}(1+\theta) \\
C_{k}^{f}=b_{k}^{f} \gamma_{m} \\
D_{k}^{f}=b_{k}^{f} \gamma_{f}
\end{gathered}
$$

Assuming two different sharing rules gives a similar identification system where the parameters of the sharing rule have the subscript $k$ indicating each participation regime.

\footnotetext{
4 There are 73 additional restrictions in each regime which equal parameters of demographic and household characteristic variables between reduced and structural forms.
} 
Table I. Sample Statistics

\begin{tabular}{|c|c|c|c|c|c|}
\hline & \multicolumn{2}{|c|}{$\begin{array}{l}\text { Non Participation Regime } \\
\quad \# 3369 \text { obs. }\end{array}$} & \multicolumn{2}{|c|}{$\begin{array}{l}\text { Participation regime } \\
\text { \# } 1509 \text { obs. }\end{array}$} & \multirow{2}{*}{$\begin{array}{l}\text { Mean Diff. } \\
\text { Ho: } \mathrm{m} 0-\mathrm{m} 1=0 \\
\text { t-ratio }\end{array}$} \\
\hline & Mean $(\mathrm{m} 0)$ & Std. Dev & Mean (m1) & Std. Dev & \\
\hline Expenditures ${ }^{1}$ on husband's clothing & 67.645 & $(120.648)$ & 90.970 & $(146.090)$ & $-5.83^{*}$ \\
\hline Expenditues on wife's clothing & 66.758 & $(116.326)$ & 115.642 & $(242.149)$ & $-9.52 *$ \\
\hline Private Expenditures/hhold. Size & 362.543 & $(208.424)$ & 500.963 & $(286.087)$ & $-18.99 *$ \\
\hline Husband's wage & 0.770 & $(0.513)$ & 0.848 & $(0.438)$ & $-5.14 *$ \\
\hline Wife's wage & 0.289 & $(0.139)$ & 0.605 & $(0.371)$ & $-43.14 *$ \\
\hline Hhold. Size & 3.696 & $(1.077)$ & 3.495 & $(1.017)$ & $6.13 *$ \\
\hline Number children aged $0-3 /$ hhold size & 0.083 & $(0.136)$ & 0.083 & $(0.139)$ & -0.11 \\
\hline Number children aged 4-8/hhold size & 0.126 & $(0.155)$ & 0.127 & $(0.157)$ & -0.20 \\
\hline Number children aged 9-14/hhold size & 0.158 & $(0.183)$ & 0.135 & $(0.174)$ & $4.25^{*}$ \\
\hline Number children aged $15-16 /$ hhold size & 0.037 & $(0.093)$ & 0.028 & $(0.082)$ & $3.40 *$ \\
\hline Husband's age & 39.278 & $(9.182)$ & 36.304 & $(7.043)$ & $11.19^{*}$ \\
\hline Husband's Primary Education & 0.234 & $(0.424)$ & 0.213 & $(0.410)$ & 1.60 \\
\hline Husband's Secondary Education & 0.182 & $(0.386)$ & 0.281 & $(0.450)$ & $-7.83 *$ \\
\hline Husband's Higher Education & 0.096 & $(0.294)$ & 0.269 & $(0.444)$ & $-16.13 *$ \\
\hline Wife's Primary Education & 0.271 & $(0.444)$ & 0.227 & $(0.419)$ & 0.00 \\
\hline Wife's Secondary Education & 0.142 & $(0.349)$ & 0.262 & $(0.440)$ & $-10.23 *$ \\
\hline Wife's Higher Education & 0.045 & $(0.206)$ & 0.283 & $(0.451)$ & $-25.35^{*}$ \\
\hline Urban Residence & 0.538 & $(0.499)$ & 0.629 & $(0.483)$ & $-5.97 *$ \\
\hline Executive & 0.085 & $(0.279)$ & 0.247 & $(0.432)$ & $-15.71 *$ \\
\hline Blue collar worker & 0.627 & $(0.484)$ & 0.528 & $(0.499)$ & $6.55^{*}$ \\
\hline Businessman & 0.132 & $(0.338)$ & 0.108 & $(0.311)$ & $2.32 *$ \\
\hline Home Ownership & 0.726 & $(0.446)$ & 0.714 & $(0.452)$ & 0.82 \\
\hline Car Ownership & 0.834 & $(0.372)$ & 0.920 & $(0.272)$ & $-8.02 *$ \\
\hline Number of durables & 9.484 & $(2.950)$ & 10.987 & $(3.344)$ & $-15.76^{*}$ \\
\hline
\end{tabular}

Notes

1. Expenditures and hourly wages on thousands pesetas

${ }^{*} *$ refers to statistical significance of the two sides test of significance at $5 \%$ level 
Table II. Reduced Form Estimates

\begin{tabular}{|c|c|c|c|c|c|c|c|c|c|c|c|c|}
\hline & \multicolumn{6}{|c|}{ Engel Curve of Husband's Clothing } & \multicolumn{6}{|c|}{ Engel Curve of Wife's Clothing } \\
\hline & $\beta 0$ & $\begin{array}{r}\mathrm{t}- \\
\text { ratio }\end{array}$ & $\beta_{1}$ & $\begin{array}{l}\text { t- } \\
\text { ratio }\end{array}$ & $\beta_{1}-\beta o$ & $\begin{array}{r}\mathrm{t}- \\
\text { ratio }\end{array}$ & $\beta o$ & $\begin{array}{r}\mathrm{t}- \\
\text { ratio }\end{array}$ & $\beta_{1}$ & $\begin{array}{r}\mathrm{t}- \\
\text { ratio }\end{array}$ & $\beta_{1}-\beta o$ & $\begin{array}{r}\mathrm{t}- \\
\text { ratio } \\
\end{array}$ \\
\hline Log(Private Expenditures/hhold. size) & 85.804 & $16.51 *$ & 126.795 & $11.99 *$ & 40.995 & $2.82 *$ & 53.896 & $6.36^{*}$ & 221.036 & $12.81 *$ & 167.140 & $7.05 *$ \\
\hline Log(husband's wage) & -12.632 & $-2.45^{*}$ & 1.326 & 0.16 & 13.957 & 1.15 & 11.171 & 1.33 & -13.006 & -0.94 & -24.177 & -1.23 \\
\hline Log(wife's wage) & 1.693 & 0.33 & 1.591 & 0.21 & -0.102 & -0.01 & -5.635 & -0.67 & 13.871 & 1.15 & 19.506 & 1.04 \\
\hline Log(hhold. size $)$ & -56.013 & -1.57 & 0.107 & 0.001 & 56.126 & 0.51 & 79.158 & 1.36 & -151.543 & -1.11 & -230.701 & -1.29 \\
\hline Number children aged 0-3/hhold size & 138.042 & $2.5^{*}$ & 32.566 & 0.29 & -105.491 & -0.69 & -79.018 & -0.88 & 229.127 & 1.24 & 308.145 & 1.24 \\
\hline Number children aged 4-8 /hhold size & 187.885 & $3.28^{*}$ & 65.448 & 0.54 & -122.445 & -0.75 & -55.105 & -0.59 & 339.118 & 1.71 & 394.223 & 1.49 \\
\hline Number children aged 9-14/hhold size & 186.900 & $3.26^{*}$ & 41.400 & 0.33 & -145.510 & -0.87 & -90.448 & -0.97 & 335.741 & 1.63 & 426.190 & 1.57 \\
\hline Number children aged $15-16 /$ hhold size & 169.509 & $2.92 *$ & 157.340 & 1.19 & -12.177 & -0.07 & -62.572 & -0.66 & 414.332 & 1.92 & 476.904 & 1.68 \\
\hline Husband's age & -1.116 & -0.56 & -3.587 & -0.87 & -2.471 & -0.45 & -5.374 & -1.65 & 0.641 & 0.09 & 6.015 & 0.67 \\
\hline Squared Husband's age & 0.014 & 0.58 & 0.038 & 0.74 & 0.024 & 0.36 & 0.064 & 1.66 & -0.009 & -0.11 & -0.073 & -0.67 \\
\hline Husband's Primary Education & -3.765 & -0.6 & 18.504 & 1.14 & 22.270 & 1.04 & 12.592 & 1.22 & -27.079 & -1.03 & -39.671 & -1.14 \\
\hline Husband's Secondary Education & 30.768 & $4.33^{*}$ & -29.171 & -1.89 & -59.935 & $-2.85^{*}$ & 17.000 & 1.47 & -20.774 & -0.83 & -37.774 & -1.1 \\
\hline Husband's Higher Education & 60.296 & $5.75^{*}$ & -36.479 & $-2.09 *$ & -96.775 & $-3.82 *$ & 23.420 & 1.37 & -17.993 & -0.63 & -41.412 & -1 \\
\hline Wife's Primary Education & 7.666 & 0.9 & -7.758 & -0.31 & -15.417 & -0.47 & -3.605 & -0.26 & 17.590 & 0.43 & 21.194 & 0.4 \\
\hline Wife's Secondary Education & -9.765 & -0.59 & 13.555 & 0.40 & 23.326 & 0.48 & 20.410 & 0.76 & 11.197 & 0.20 & -9.213 & -0.12 \\
\hline Wife's Higher Education & 15.381 & 0.4 & -11.026 & -0.23 & -26.401 & -0.33 & 41.514 & 0.65 & 53.752 & 0.69 & 12.238 & 0.09 \\
\hline Urban Residence & -12.718 & $-3.41^{*}$ & 24.225 & $3.26^{*}$ & 36.940 & 3.6 & -4.766 & -0.78 & -20.745 & -1.71 & -15.980 & -0.96 \\
\hline Executive & 3.443 & 0.39 & 28.915 & $2.49^{*}$ & 25.478 & 1.39 & 14.413 & 1 & -31.699 & -1.68 & -46.112 & -1.55 \\
\hline Blue collar worker & 1.949 & 0.37 & 0.491 & 0.04 & -1.458 & -0.1 & -4.927 & -0.58 & 1.646 & 0.09 & 6.573 & 0.27 \\
\hline Businessman & -9.667 & -1.45 & 5.050 & 0.34 & 14.720 & 0.74 & -15.441 & -1.42 & -0.294 & -0.01 & 15.147 & 0.47 \\
\hline Home Ownership & 2.397 & 0.57 & 3.683 & 0.48 & 1.285 & 0.12 & 13.383 & $1.96^{*}$ & -26.314 & $-2.11^{*}$ & -39.697 & $-2.24 *$ \\
\hline Car Ownership & -3.092 & -0.57 & -41.287 & $-2.99 *$ & -38.196 & $-2.13^{*}$ & -14.449 & -1.63 & 16.538 & 0.73 & 30.987 & 1.06 \\
\hline Number of durables & -3.187 & $-4.33^{*}$ & 3.596 & $2.94 *$ & 6.783 & $3.8^{*}$ & 1.500 & 1.25 & 1.593 & 0.80 & 0.093 & 0.03 \\
\hline Intercept & -373.623 & $-6.24 *$ & -663.962 & $-4.87^{*}$ & -290.383 & -1.67 & -248.579 & $-2.54 *$ & -1283.258 & $-5.77 *$ & -1034.680 & $-3.65^{*}$ \\
\hline Selectivity term & -25.586 & -0.38 & & & & & 150.326 & 1.38 & & & & \\
\hline F-test for 16 Region fixed effects & $80.82 *$ & & & & $70.86^{*}$ & & $31.85^{*}$ & & & & $40.99 *$ & \\
\hline \multicolumn{13}{|c|}{ Hansen J statistic (overidentification test of all instruments) Chi(2) ${ }^{1}$ : } \\
\hline Men's Clothing: & 0.177 & & & & & & & & & & & \\
\hline Women's Clothing & 4.190 & & & & & & & & & & & \\
\hline
\end{tabular}

\section{Notes:}

1. There are two overidentification restrictions in each Engel curve

'*' refers to statistical significance of the two sides test of significance at $5 \%$ level 
Table III. Reduced Form Model Restrictions

\begin{tabular}{lrrr}
\hline & Wald test & degrees of freedom & p-value \\
\hline Income Pooling & 11.970 & 4 & 0.017576 \\
Distribution Factor Proportionality & 0.612 & 2 & 0.736235 \\
Equal Sharing Rule & 5.303 & 6 & 0.505589 \\
\hline
\end{tabular}

Table IV. Sharing Rule Estimates ${ }^{1}$

\begin{tabular}{lrrr}
\hline & \multicolumn{2}{c}{ Unique Sharing Rule } & Two Sharing Rules \\
& & Non Participation & \multicolumn{1}{c}{ Participation } \\
\cline { 2 - 4 } & $-0.983832^{*}$ & $-0.861546^{*}$ & $-1.023338^{*}$ \\
$\gamma_{\mathbf{m}}$ & $(0.00586)$ & $(0.05762)$ & $(0.09920)$ \\
& $0.028559^{*}$ & $0.262676^{*}$ & $0.025685^{*}$ \\
$\gamma_{\mathbf{f}}$ & $(0.00809)$ & $(0.10048)$ & $(0.01062)$ \\
& 0.005776 & 0.021801 & -0.02601 \\
Derivatives of the wife's share ${ }^{2}$ (evaluated at equal sharing) & $(0.03479)$ & $(0.08335)$ \\
$\partial \mathbf{x}^{\mathbf{f}} / \partial \mathbf{M}$ & $0.00808^{*}$ & & \\
& $(0.00293)$ & $0.06923^{*}$ & -0.011669 \\
& $\mathbf{f} \mathbf{f} / \partial \mathbf{w}_{\mathbf{m}}$ & $(0.02881)$ & $(0.04960)$ \\
$\partial \mathbf{x}^{\mathbf{f}} / \partial \mathbf{w}_{\mathbf{f}}$ & $0.51428^{*}$ & $0.63134^{*}$ & $0.51284^{*}$ \\
& $(0.00404)$ & $(0.05024)$ & $(0.00531)$ \\
\hline
\end{tabular}

Test of Overidentification Restrictions

Chi-Squared (5)

18.824708

p-value

Notes:

0.002072
Chi-Squared (2)

0.665909 0.716803

1 The structural form includes all the demographic variables except variables of household composition

2. These derivatives are estimated according to equations (9) and (11) at $\varphi=0.5$

*' refers to statistical significance of the two sides test of significance at $5 \%$ level 
Table V. Structural form of the individual Engel Curves ${ }^{1}$

\begin{tabular}{lrrrrrrrr}
\hline & \multicolumn{3}{c}{ Husband's Engel Curve for his clothing } & \multicolumn{3}{c}{ Wife's Engel Curve for her clothing } \\
& \multicolumn{3}{c}{ Non-participation } & Participation & \multicolumn{3}{c}{ Non-participation } & \multicolumn{3}{c}{ Participation } \\
\hline & & & & & & t- & t- \\
Variable & Parameter & t-ratio & Parameter & t-ratio & Parameter & ratio & Parameter & ratio \\
ln x & 46.1367 & $14.68^{*}$ & -0.4645 & -0.48 & 235.9928 & $2.76^{*}$ & 490.7633 & 0.31 \\
Husband's age & 3.4424 & 0.39 & 18.9867 & 0.57 & 17.4630 & 1.51 & 0.5769 & 0.09 \\
Squared Husband's age & 1.8126 & 0.35 & -4.3703 & -0.09 & 23.8318 & 1.39 & -0.0083 & -0.10 \\
Husband's Primary Ed. & -9.5916 & -1.44 & 24.4107 & $3.29^{*}$ & -4.2180 & -0.31 & -28.7887 & -1.10 \\
Husband's Secondary Ed. & 2.5412 & 0.60 & 28.6840 & $2.48^{*}$ & 19.9994 & 0.74 & -21.7646 & -0.87 \\
Husband's Higher Ed. & -2.9898 & -0.55 & 0.6680 & 0.06 & 40.8387 & 0.64 & -18.8657 & -0.67 \\
Wife's Primary Ed. & -3.1956 & $-4.36^{*}$ & 5.0234 & 0.34 & -4.7771 & -0.78 & 19.1553 & 0.47 \\
Wife's Secondary Ed. & -4.1298 & -0.45 & 3.5975 & 0.47 & 14.4116 & 1.00 & 12.5176 & 0.23 \\
Wife's Higher Ed. & 32.4196 & $2.38^{*}$ & -41.4398 & $-3.0^{*}$ & -4.9600 & -0.58 & 55.3695 & 0.72 \\
Urban Residence & -46.6791 & $-3.36^{*}$ & 3.6149 & $2.96^{*}$ & -15.4224 & -1.42 & -20.7000 & -1.71 \\
Executive & -15.5952 & -1.52 & 51.9328 & 3.13 & 13.4183 & 1.95 & -31.7549 & -1.68 \\
Blue collar worker & 55.2581 & $3.79^{*}$ & -11.9284 & -0.40 & -14.4244 & -1.63 & 1.6893 & 0.09 \\
Businessman & 6.4089 & 1.04 & 5.3451 & 0.23 & 1.4982 & 1.25 & -0.3004 & -0.01 \\
Home Ownership & 22.6392 & $3.17^{*}$ & 33.2848 & 1.42 & 16.0054 & 1.08 & -26.3349 & $-2.1 *$ \\
Car Ownership & -13.4335 & -1.61 & -2.5315 & -0.09 & 30.2254 & 1.36 & 16.5005 & 0.73 \\
Number of durables & 3.4079 & 0.45 & 29.9857 & $2.27^{*}$ & -38.0999 & -1.68 & 1.5977 & 0.80 \\
\hline
\end{tabular}

Notes:

1. Includes all demographic and regional variables except household composition variables. The estimation includes regional fixed effects. 
Table VI. Sample Selection

Couples, with or without children aged less than 17, in which the man and the 6694 woman are less than 66 years old

If the man works more than 13 hours per week, he declares positive labour income, and it can be imputed his weekly working hours

Dropped observations:

If the woman works but does not declare income

If there are inconsistencies in the type of employment declared by the woman and the relationship with the economic activity

If the woman does not work but she declares some labour income

50

If the woman reports working part-time

Sample selected 4946

Households in the participation regime 1509

Households in the non-participation regime 


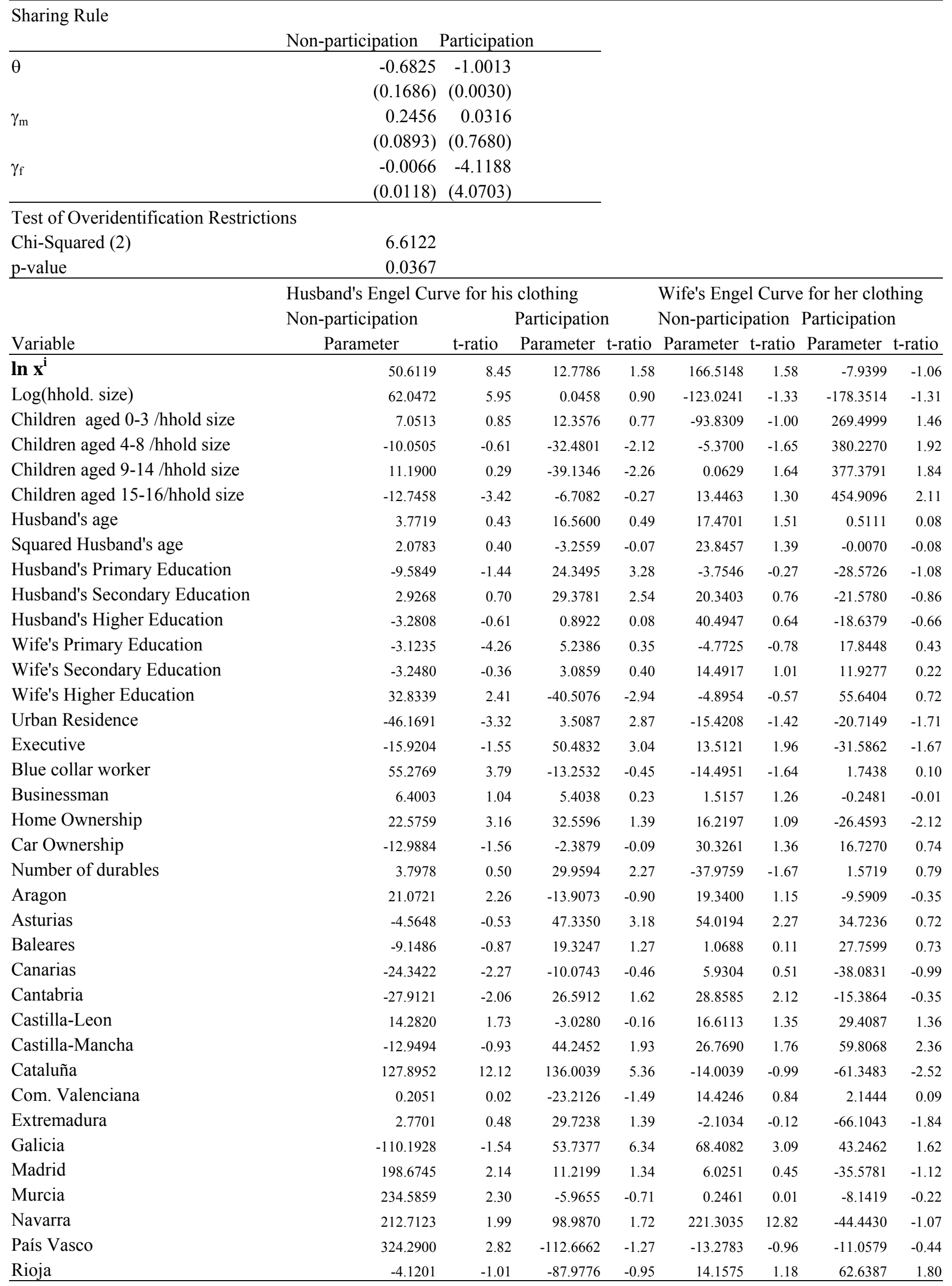


Table VIII. Female Wage and Participation Equations

\begin{tabular}{lrrlrr}
\hline Participation Equation & \multicolumn{3}{c}{ Wage Equation } & Coef. & t-ratio \\
\hline Log(Husband's Wage) & Coef. & t-ratio & & 0.1085 & 5.54 \\
Husband's working hours & -0.3796 & -8.60 & Woman's age & -0.0013 & -5.58 \\
Woman's age & -0.0130 & -2.22 & Squared woman's age & 0.2674 & 0.97 \\
Squared woman's age & 0.1082 & 3.14 & Woman's Primary Education & 0.8129 & 3.05 \\
Husband's age & -0.0018 & -4.01 & Woman's Secondary Education & 0.5139 & 1.99 \\
Square of Husband's age & -0.0453 & -1.26 & Woman's Higher Education & 0.0033 & 0.41 \\
Woman's Primary Education & 0.0005 & 1.21 & Woman's age* Primary Education & -0.0025 & -0.33 \\
Woman's Secondary Education & -0.0506 & -0.16 & Woman's age* Secondary Ed. & 3.18 \\
Woman's Higher Education & -0.0835 & -0.24 & Woman's age* Higher Education & 0.0229 & -8.99 \\
Husband's Primary Education & 0.1536 & 0.36 & Intercept & -3.6532 & \\
Husband's Secondary Education & 0.9242 & 2.72 & & 0.2647 \\
Husband's Higher Education & 0.8163 & 2.36 & rho & $(0.070)$ \\
Woman's age* Primary Education & 1.2074 & 2.96 & & 0.6788 \\
Woman's age* Secondary Education & 0.0092 & 0.98 & sigma & $(0.015)$ \\
Woman's age* Higher Education & 0.0244 & 2.42 & & $10.35^{*}$ \\
Husband's age* Primary Education & 0.0401 & 3.32 & LR(rho=0) & \\
Husband's age* Secondary Education & -0.0240 & -2.60 & & \\
Husban's age* Higher Education & -0.0178 & -1.90 & & \\
Number of children aged 4-8 & -0.0246 & -2.29 & & \\
Number of children aged 0-3 & -0.3631 & -8.17 & & \\
Number of children aged 9-14 & -0.1322 & -3.97 & & \\
Number of children aged 15-16 & -0.0715 & -2.33 & & \\
Regional Unemployment & -0.0010 & -0.02 & & \\
Intercept & -0.0138 & -6.56 & & \\
\hline
\end{tabular}

